\title{
Discussion on the Planning and Design Elements of the Sheltered Anchorage
}

\author{
Mingyan Zhong ${ }^{1}$ and Wanzheng $\mathrm{Ai}^{2, \text { * }}$ \\ ${ }^{1}$ Marine College of Zhejiang Ocean University, Zhoushan 316000, P. R. China \\ ${ }^{2}$ Marine College of Zhejiang Ocean University, Zhoushan 316000, P. R. China \\ a3248207594@qq.com, baiwanzheng@163.com
}

\section{Keywords: Sheltered anchorage; Anchorage selection; Anchorage planning}

\begin{abstract}
China is located in the Northwest Pacific. The monsoon climate is obvious, so the sheltered anchorage has an important effect on the development of water transportation in China. In order to better play the role of protecting the ship in the sheltered anchorage, the probability of collision between the anchor and the ship in the sheltered anchorage is reduced. This paper analyzes the causes of ship collision in sheltered anchorage, it is pointed out that there are some problems such as the anchorage area and insufficient water depth, the poor natural condition of anchorage, the unsuitable geology of anchorage and the imperfect infrastructure of anchorage. Therefore, through the determination of reasonable area and depth of the typhoon Anchorage, select the waters with good natural conditions, establish the supporting facilities which are suitable for the anchorage, and provide some ideas for the planning and design of the typhoon Anchorage.
\end{abstract}

\section{Introduction}

Anchorage, berth, ship and waterway are the key points of marine transportation, in which the choice and planning of Anchorage play an important role in the layout of the port, the safety of ship's maritime transportation and the economy of maritime transportation. An important influence factor of port location and layout is the planning and design of various anchorage in the vicinity of Port. [1] In recent years, China's maritime transport and port transport has developed very rapidly, the ship's large-scale and larger and more obvious. The phenomenon of the congestion and stagnation of ships is more and more, especially in the sheltered Anchorage, due to the need for sheltered, large influx of ships easily caused Anchorage congestion, while the Anchorage planning and design of improper and some unreasonable or even wrong anchoring method easily causes the ship to take the anchor, broken chain phenomenon, which leads to collision between ships, In view of the economic losses, the planning and design of the sheltered anchorage is very necessary.

\section{Anchorage planning and design principles}

The principle of planning and design of the harbor sheltered anchorage should be based on the requirements of anchorage layout and the local natural environment.

The planning and design of anchorage should be adapted to the requirements of waterway setting, port layout development and national defense construction. First, the planning and design should be based on the existing waterway, port layout and the development status of port planning. Secondly, the layout and disposition of Anchorage should be suitable for the development of waterway and port in the future, and should meet the requirements of the corresponding national defense construction.

Adhering to the concept of rational utilization of resources and sustainable development, balancing the relationship between Anchorage planning and anchorage Construction and anchorage development. In the planning of anchorage, we should not only pay attention to the utilization of water resources, but also consider the use of underwater resources, the design of port Anchorage should also be compatible with the size of the existing port, so as to promote the overall sustainable development of anchorage. 
Good anchorage must meet certain natural conditions, in addition to a wide range of areas of good vision, deep waters, stable and small currents and currents, and suitable for anchoring the bottom of the seabed, there are social conditions, such as the Anchorage, which, as a result of the large anchorage area, will span two different cantons, If the development and construction of Anchorage, two of ports cannot cooperate with each other to develop the anchorage easily lead to unreasonable development, resulting in waste of resources. In the planning and design of Anchorage, Hong Kong should co-operate with each other to build anchorage. [2]

The planning and layout of the anchorage should take into account the ship's arrival, departure, berthing and pilotage. In order to facilitate the safe entry and exit of the port, the anchorage should be set up in the port area and near the harbor channel. [3] Several functions of different anchorage, the distance is not too far, convenient for ships to enter the port.

\section{Analysis of influencing factors on selection of sheltered anchorage}

The choice of sheltered anchorage directly affects the effectiveness and safety of the ship in the sheltered anchorage. First of all, when choosing the position of the sheltered anchorage, it is easy to find the ship to anchor the sheltered anchorage. Secondly, the sheltered anchorage should be coordinated with the port area and the harbor channel, so that the ship can enter and exit the port conveniently after anchoring in the sheltered anchorage. On this basis, several factors which affect the safety of ship anchoring in the sheltered anchorage should be fully considered. [4] There are mainly the following aspects: 1 , the natural condition of the sheltered anchorage 2, the mooring vessel's own condition 3, the port condition near the anchorage and the ship density.

\section{Depth and scope of anchorage}

Because the depth of the anchorage is varied and the ship is different because of its own tonnage, the ship mooring should be partitioned. [5] ship draught, nautical chart depth, high tide, the size of the water flow, the power of the anchor machine, etc. are the main factors to be considered in determining the depth of anchorage. In the planning of the anchorage of the sheltered anchorage, the tonnage of the ship anchored at Anchorage should be considered, and the depth of water required for different types and tonnage of ships is different, and the depth of water required by different vessels is mainly determined by the draught and the wave size of the ship. The planning of sheltered anchorage, the determination of water depth, to fully consider the various circumstances. Generally speaking, in the typhoon effect good, no big wave anchorage, anchorage of water depth in low tide should also be able to ensure the safety of the ship anchoring. The anchoring depth is generally 1.5 times the depth of the draught or $1 / 4$ of the length of the anchor chain. [6] When the sea waves are larger, we should take full account of the influence of large waves on the mooring of ships, and increase the wave surplus depth to ensure the safety of anchoring. When the water depth is sufficient, the maximum power of the windlass and the length of the anchor should be considered to avoid anchoring more than the maximum depth.

In determining the scope of the sheltered anchorage, we mainly consider three factors. One factor is the density of the ship in the area. The density of a ship is the ratio of the quantity of a ship to the area of a unit of water in a certain instant. It can reflect the quantity and intensity of a ship in a certain water area and the utilization of anchorage to obtain the heavy and dangerous degree of ship traffic in a certain water area. The density of ships is determined by the number and size of the surrounding ports. [7] The ship density is too large, the ship's anchoring safety has a significant impact, the ship density too small cannot fully play the role of Anchorage, resulting in waste of resources. In planning the sheltered anchorage, we should fully consider the density of the ship in the area and determine the appropriate range. [8] Another factor to consider is the way the ship is moored, with two types of berthing in Anchorage, one buoy mooring and the other anchored. Buoy mooring means the mooring of a ship with a mooring or anchor chain that is used to leave a mooring at a fixed point in the anchorage or within the waters of the harbor. Anchoring means the berthing method which makes the ship stay at a certain point of Anchorage by anchoring force. The berthing method determines the mooring area. Another factor affecting the anchorage area is the maneuver of the ship. When anchoring, it is necessary to have enough roundabout waters, such 
factors as hydrological and meteorological conditions, initial chain length, length of vessel, depth of water, etc.

\section{The bottom of the anchorage}

The base of the so-called Anchorage is the type of surface matter at anchor. [9] There are two kinds of the classification of the bottom quality, and a classification method is based on the smooth degree of the throwing anchor to classify the bottom quality as safety bottom quality and dangerous substrate. Safety substrates generally have mud, sand, silt mixed, flat rock, gravel, shells, seaweed and flat coral, etc., in these substrates, whether anchor or anchor can be carried out smoothly. And reefs, corals and so on are called dangerous substrates, on these substrates for anchoring operations is very dangerous, often occurs in the card anchor or chain fault. Another classification method is based on the strength of the anchor in the seabed can be obtained by the size of the geology into a good substrate and undesirable substrate. Good bottom quality generally has mud, sand, silt mixed, and bad bottom quality generally have flat rock, gravel, flat coral, seaweed and shells. The grasping force obtained after anchoring is mainly related to the geology of Anchorage, for anchoring Anchorage, the seabed geology needs to be hard and soft, preferably safe geology and good geology, so that the anchor can get enough grasping force to fix the ship. The concept of the base is very important in navigation, because the captain and the pilot can calculate how much grip and drag the anchor and chain can obtain after the ship has thrown the anchor to the bottom of the sea. The sheltered anchorage and other anchorage is different, the sheltered anchorage needs a better seabed geology to let the ship anchor, so that the ship can rely on anchor to grasp the seabed in the wind and waves without taking the anchor, breaking chain, and then collision with other ships. Therefore, in planning the sheltered anchorage, the selected sea areas should be scanned and bottom-quality sampling, and then determine whether suitable as the water of the anchorage.

\section{Wind, wave and flow of Sheltered anchorage}

In particular, the impact of wind on anchorage should be considered as a sheltered anchorage. Sheltered anchorage should be located outside the harbor with natural barriers to the waters, mountains, islands, buildings and land can become a good natural barrier to ship the typhoon. The islands can block winds and waves from a certain direction, on the one hand, these islands have a certain height, which can obstruct the march of the wind and provide a powerful shielding for the ships in the harbor, thereby reducing the wind waves in the harbor and the wind force on the ships; In addition, land and mountains can also play a role in the wind and waves. For the wind of the sheltered anchorage, the wind direction and wind speed are mainly considered. A detailed statistic on the wind speed of the mooring waters over the years, and a careful statistic of the typhoon in the waters. [10] A more reasonable assessment of the risk of the waters to determine the suitability of the sea area as a sheltered anchorage. [11]

The influence of wave on mooring safety of ship mainly has the following aspects: (1) the influence of wave on the mooring safety of ship is not obvious when the wave is small, which is mainly caused by the transverse inclination and sway of the ship's small angle. (2)After the wave reaches a certain degree, the influence of wave on the ship becomes obvious, and the transverse inclination angle of the ship becomes bigger and the sway is more obvious, which poses a certain danger to the safety of the mooring. (3)There will have a great influence on the mooring of the ship when the wave is large, the larger the wave will cause the ship to tilt and sway greatly, which leads to the ship's anchor. The effect of wave on the ship and the role of the wind on the ship have the same point also have different points, the main difference is in the windy time, the waves are relatively large, and the wind becomes smaller, the impact of the waves on the ship to continue a certain amount of time. Anchorage to want to shelter, first of all to bring down the waves, which requires the wind and the surrounding terrain can play the role of shelter, in the larger wave conditions can also provide a relatively calm surface of the ship.

The flow of the anchorage is generally composed of both current and tidal currents, and the confluence of currents and tidal currents forms the currents. When the direction of the flow and the wind to the same, the ship will constitute a major security hidden trouble, which is very easy to take the anchor, broken chain and then lead to the collision of ships. Therefore, in planning the sheltered 
anchorage, should carefully consider the anchorage of the water flow on the impact of the ship. The selection of Anchorage should be a relatively stable internal flow, no reflux phenomenon, low velocity of the sea area as a sheltered anchorage.

\section{Other factors to be considered in Anchorage planning}

At sea, we generally can see the distance within 4000 meters is known as poor visibility. In planning the sheltered anchorage, we should consider the grading standard of international fog, set up the hazard evaluation of the visibility of the berthing waters, and determine whether the land is suitable for the sheltered anchorage.

In the planning of Sheltered anchorage, we should also consider whether there are marked landmarks in Anchorage. When a ship is anchored in Anchorage, it is often necessary to use the object label to determine its position and distance. The object is divided into two categories: natural object Standard and artificial object standard. Natural objects are mainly hills, islands, Hai, etc., artificial objects marked with lighthouse, lamp pile, buoy, breakwater and other notable fixed structures. In the planning of sheltered anchorage, as far as possible to make the anchorage around a marked object. [12]

\section{Conclusion}

The sheltered anchorage is a kind of special anchorage, which can easily lead to the accident of the ship's anchor and broken chain, which leads to the economic loss caused by the collision of ships. Based on the general principle of choosing the sheltered anchorage, this paper in the planning of the sheltered anchorage, we should consider the influence of the anchorage scope, water depth, bottom quality, wind, wave and flow, and briefly describe the problems that should be paid attention to in the planning of the Sheltered anchorage, and ensure that the sheltered anchorage can play the role of protecting the ship. It provides a reference basis for the construction of sheltered anchorage.

\section{References}

[1] S.Q. Chen: Study on Reasonable Distribution and Optimum Design of Port Anchorage (MS.,Dalian Maritime University,China 2007),p.

[2] L.B. Xu: Study on Anchorage Planning of Zhoushan Port (MS.,Shanghai Maritime University,China 2005),p.

[3] S.L. Zhu: "Big Port Small Anchorage" Contradiction Will Greatly Alleviate [N]. Zhoushan Daily, 2013-11-28 (001).

[4] X.F. Liu: Analysis of Factors Affecting Anchoring Safety (Ph.D.,Dalian Maritime University,China 2009),p.

[5] G. Wang, G.Q. Chen, Z.X. Wang, X. Li and Y.S. Chen: China Aquatic Products,(2013) No.4,p.22-25.

[6] H.B. Xie: Study on Water Depth of Anchorage (Ph.D.,Dalian Maritime University,China 2011),p.

[7] X. Tian: Research on the Ship Field in Specific Waters (Ph.D.,Dalian Maritime University,China 2009),p.

[8] J.T. Pei: Simulation Study on the Eccentric Movement and the Process of the Anchoring of Single Anchored Ship in Wind (Ph.D.,Dalian Maritime University,China 2010),p.

[9] B. Tian and T.T. Zhang: Logistics Engineering and Management Vol. 33 (2011)No.7,p.120-121.

[10]C. Zhao, S.G.Luan and L.Y. Xia: Value Engineering, Vol. 33 (2014)No.(28),p.287-288.

[11]X.H. Zhu and L.Y. Zheng: Tianjin Navigation, (2015)No.(01),p.3-4.

[12] Announcement on the publication of the local revision of the general design Code of the Seaport (JTJ211-99) (design of the Ship-scale section) Urban road bridge with Flood control, (2008), No.4,p.107. 